\title{
Rapid Approach to Determine Propionic and Sorbic Acid Contents in Bread and Bakery Products Using ${ }^{1} \mathbf{H}$ NMR Spectroscopy
}

\author{
Marwa Scharinger ${ }^{1}$, Marcel Kuntz ${ }^{2}$, Andreas Scharinger ${ }^{2}$, Jan Teipel ${ }^{2}\left(\right.$ ) , Thomas Kuballa ${ }^{2}$, Stephan G. Walch ${ }^{2}(\mathbb{B}$ \\ and Dirk W. Lachenmeier $2, *$ (D) \\ 1 Unit of Research of Plant Ecology, Faculty of Sciences, Campus Academia, University of Tunis El-Manar II, \\ Tunis 2092, Tunisia; marwa.scharinger@outlook.com \\ 2 Chemisches und Veterinäruntersuchungsamt (CVUA) Karlsruhe, D-76187 Karlsruhe, Germany; \\ marcel.kuntz@cvuaka.bwl.de (M.K.); andreas.scharinger@cvuaka.bwl.de (A.S.); \\ jan.teipel@cvuaka.bwl.de (J.T.); thomas.kuballa@cvuaka.bwl.de (T.K.); \\ stephan.walch@cvuaka.bwl.de (S.G.W.) \\ * Correspondence: lachenmeier@web.de; Tel.: +49-721-926-5434
}

check for updates

Citation: Scharinger, M.; Kuntz, M.; Scharinger, A.; Teipel, J.; Kuballa, T.; Walch, S.G.; Lachenmeier, D.W. Rapid Approach to Determine Propionic and Sorbic Acid Contents in Bread and Bakery Products Using ${ }^{1} \mathrm{H}$ NMR Spectroscopy. Foods 2021, 10, 526. https://doi.org/10.3390/foods 10030526

Academic Editor: Thierry Aussenac

Received: 2 February 2021

Accepted: 28 February 2021

Published: 3 March 2021

Publisher's Note: MDPI stays neutral with regard to jurisdictional claims in published maps and institutional affiliations.

Copyright: (c) 2021 by the authors. Licensee MDPI, Basel, Switzerland. This article is an open access article distributed under the terms and conditions of the Creative Commons Attribution (CC BY) license (https:/ / creativecommons.org/licenses/by/ $4.0 /)$.

\begin{abstract}
The food additive sorbic acid is considered as an effective preservative for certain cereal products, and propionic acid is commonly added in bakery wares, e.g., bread and fine bakery wares. The aim of this study was to develop and validate a new nuclear magnetic resonance spectroscopy $\left({ }^{1} \mathrm{H} \mathrm{NMR}\right)$ method for the routine screening and quantification of sorbic and propionic acids in bread and several bakery products for quality control purposes. Results showed that none of the screened samples contained higher concentrations than regulatory maximum limits. However, for some samples, labelling of preservatives was lacking or they were used in food categories, for which the use is not approved. It can be concluded that the developed NMR method can be used for the routine screening of bakery products.
\end{abstract}

Keywords: bread; NMR spectroscopy; propionic acid; quality control; sorbic acid

\section{Introduction}

Bread has been considered as one of the most important human staple foods. The use of food additives to enhance shelf life also dates back to ancient history [1]. The World Health Organization (WHO) and the Food and Agriculture Organization (FAO) of the United Nations have defined food additives as substances "which are added intentionally to food, generally in small quantities, to improve its appearance, flavor, texture, or storage properties" $[2,3]$.

It has been postulated that sorbic acid and propionic acid may be safely used as antimicrobial agents (Annex II to EC regulation number 1333/2008) [4,5]. Both food additives may be used in prepackaged sliced bread and rye bread. In addition, its use is also allowed in pre-baked and packaged bakery products, as well as in energy-reduced bread, partially baked, prepacked bread and prepacked rolls, tortilla and pitta, boller and dansk flutes [4].

Sorbic acid (2,4-hexadienoic acid, E 200) is a straight-chain monocarboxylic acid, while potassium sorbate (E 202) is its potassium salt. Sorbic acid and potassium sorbate are white and crystalline powders. Potassium sorbate is soluble in alcohol and freely soluble in water, while sorbic acid is less soluble in alcohol and ether and only slightly soluble in water [6].

The safety of propionic acid (E 280) and its salts (E 281-283) as a food additive was re-evaluated in 2019 by the European Food Safety Authority (EFSA) Panel. No safety concerns for consumers were identified [7].

In the EU, propionic acid has maximum permitted levels for use in bread and rolls ranging from 1000 to $3000 \mathrm{mg} / \mathrm{kg}$ [4]. Both the EU Scientific Committee for Food and the 
Joint FAO/WHO Expert Committee on Food Additives have evaluated propionic acid as food additive on several occasions in 1974, 1973 and in 1990. The latter defined the acceptable daily intake as "not limited" for propionic acid and its sodium, potassium, and calcium salts [5,8]. Nevertheless, EU legislation allows the use only in certain food categories when specified maximum levels are upheld (Table 1).

Table 1. Maximum permitted levels (MPLs) of propionic acid/propionates (E 280-283) and sorbic acid/sorbates (E 200-202) in bread and bakery products according to the Annex II of Regulation (EC) No 1333/2008-levels are expressed as free acid [4].

\begin{tabular}{|c|c|c|c|}
\hline & $\begin{array}{c}\text { Bread and Bakery } \\
\text { Type }\end{array}$ & Restrictions/Exceptions & $\begin{array}{l}\text { Maximum Level (mg/L or } \\
\mathrm{mg} / \mathrm{kg} \text { as Appropriate) }\end{array}$ \\
\hline \multirow{4}{*}{$\begin{array}{l}\text { Propionic } \\
\text { acid }\end{array}$} & Bread and rolls & Only prepacked sliced bread and rye bread & 3000 \\
\hline & Bread and rolls & $\begin{array}{l}\text { Only energy-reduced bread, partially baked prepacked } \\
\text { bread and prepacked rolls, tortilla and pitta, prepacked } \\
\text { polsebrod, boller and dansk flutes }\end{array}$ & 2000 \\
\hline & Bread and rolls & Only prepacked bread & 1000 \\
\hline & Fine bakery wares & $\begin{array}{l}\text { Only prepacked fine bakery wares (including flour } \\
\text { confectionery) with a water activity of more than } 0.65\end{array}$ & 2000 \\
\hline \multirow[t]{2}{*}{ Sorbic acid } & Bread and rolls & $\begin{array}{l}\text { Only prepacked sliced bread and rye-bread, partially } \\
\text { baked, prepacked bakery wares intended for retail sale } \\
\text { and energy-reduced bread intended for retail sale }\end{array}$ & 2000 \\
\hline & Fine bakery wares & Only with a water activity of more than 0.65 & 2000 \\
\hline
\end{tabular}

Nuclear magnetic resonance spectroscopy has been developed for routine quality control as well as the detection of harmful substances in various foodstuffs, such as alcoholic beverages and coffee [9]. The NMR technique provides replicable data and elucidates definite fingerprints that have been proven suitable for authenticity testing. Thus far, only high-performance liquid chromatography, gas chromatography and gas chromatography/mass spectrometry are the validated analytical methods for the determination of preservatives and food contaminants, including cereal products [10-12]. However, NMR has several advantages, such as the small amounts required for sample preparation and the reduced time of experimentation. It can be regarded as a key method for the quantification of specific compounds from different food matrixes. All parameters that are fundamental to calculate a certain concentration out of the spectrum are directly provided by the NMRexperiment, the chemical identity of the molecule investigated, and its quantity using an internal or external reference [13,14].

The aim of this study was to extract sorbic and propionic acids from the complex bread matrix in a short time by automated steam distillation (less than five minutes) and to quantify them precisely and reliably using ${ }^{1} \mathrm{H}$ NMR for quality control and food surveillance purposes.

\section{Materials and Methods}

\subsection{Chemicals}

Reagents and standard compounds were of analytical or HPLC grade. Deuterated water $\left(\mathrm{D}_{2} \mathrm{O}\right)$ was purchased from Deutero $\mathrm{GmbH}$ (Kastellaun, Germany). The 3(trimethylsilyl)propion-2,2,3,3- $\mathrm{d}_{4}$ acid, Na salt (TSP), sulfuric acid $\left(\mathrm{H}_{2} \mathrm{SO}_{4}\right)$, potassium disulfate $\left(\mathrm{KHSO}_{4}\right.$ ), chemicals to prepare a buffer solution (mixture of $10 \mathrm{~mL}$ of $\mathrm{D}_{2} \mathrm{O}, 7.5 \mathrm{~g}$ of monosodium phosphate $\left(\mathrm{NaH}_{2} \mathrm{PO}_{4}\right), 1000 \mathrm{mg}$ of phosphoric acid $\left(\mathrm{H}_{3} \mathrm{PO}_{4} 85 \%\right)$ with a $\mathrm{pH}$ of 3.2) and propionic and sorbic acids standard solutions were all purchased from Sigma-Aldrich (Steinheim, Germany).

\subsection{Sample Preparation}

Bread and bakery products samples were randomly selected from German markets on several occasions for two projects conducted in 2017 and 2019. Samples were stored at $-18{ }^{\circ} \mathrm{C}$ before analysis. The sample preparation was based on steam distillation speci- 
fied in the German Official Method for the determination of propionic acid in bread [15]. However, automated instead of manual steam distillation was applied. To achieve this, $10 \mathrm{~g}$ of ground sample was filled up into a $750 \mathrm{~mL}$ Kjeldahl flask of the automated distillation device (Vapodest 200, Gerhardt GmbH \& Co. KG, Königswinter, Germany) set at $75 \%$ of steam power. For more details on the automated steam distillation device, see Lachenmeier et al. [16].

Then, a mixture of $10 \mathrm{~g}$ of $\mathrm{KHSO}_{4}, 0.5 \mathrm{~mL}$ of sulfuric acid $(7.1 \mathrm{M})$ and $3 \mathrm{~mL}$ of $\mathrm{D}_{2} \mathrm{O}$ were added. Each distillation into a volumetric flask prefilled with some water to encompass the outlet tube lasted four minutes; following that the volumetric flask was adjusted to $100 \mathrm{~mL}$ with demineralized water. After shaking of the volumetric flask, $500 \mu \mathrm{L}$ of the distillate was pipetted into an NMR tube and mixed thereafter with $60 \mu \mathrm{L}$ of TSP $/ \mathrm{D}_{2} \mathrm{O}$ solution $(10 \mathrm{mg} / \mathrm{mL})$ and $60 \mu \mathrm{L}$ of buffer solution.

\subsection{NMR Analysis at $400 \mathrm{MHz}$}

All NMR measurements were performed on a Bruker-Avance 400 Ultra-shield spectrometer (Bruker Biospin, Rheinstetten, Germany) equipped with a $5 \mathrm{~mm}$ selective inverse probe (SEI) with Z-gradient coils, using a Bruker Automatic Sample Changer (B-ACS 60, Bruker Biospin, Rheinstetten, Germany). The ${ }^{1} \mathrm{H}$ NMR spectra were acquired using the noesygppr1d_d7 pulse program with a time domain (TD) of 131072, 4 dummy scans (DS), 32 scans (NS), sweep width of 20.5617 ppm (SW), the spectral width in Hertz was $8223.685 \mathrm{~Hz}(\mathrm{SWH})$, additional delay (D7) of $50 \mathrm{~s}$, and an acquisition time of $7.696 \mathrm{~s}$. Receiver gain (RG) was set to 32 and a relaxation delay (D1) of $4 \mathrm{~s}$. A pulse calibration for optimization was performed before every measurement. The pulse calibration program for the optimization of pulse lengths, the size of the processed data (SI) was 262,144, the window multiplication mode was exponential (WDW EM), and the Lorentzian broadening factor for exponential window multiplication (LB) was $0.3 \mathrm{~Hz}$. The spectra were automatically phased and base-line corrected using Topspin version 3.2 and 3.5 (Bruker Biospin, Rheinstetten, Germany).

\subsection{Validation}

Propionic acid and sorbic acid were added to $10 \mathrm{~g}$ of bread. The final spiking levels were 250, 500, 1000, 2000 and $3000 \mathrm{mg} / \mathrm{kg}$. The spiked samples were prepared as described above in Section 2.2. For the determination of linearity, limits of detection, quantification, and recoveries, four concentration levels ranging from 200 to $2500 \mathrm{mg} / \mathrm{kg}$ were used. Each of them was prepared five times, measured, and evaluated.

\subsection{Data Analysis and Quality Control}

Peak areas in the ${ }^{1} \mathrm{H}-\mathrm{NMR}$ spectra were evaluated using a MatLab script. The peak areas were set on using trapezoidal integration. Quantification was performed using the Electronic-REference To access In vivo Concentrations (ERETIC) factor, as previously described [9].

\section{Results}

\subsection{Validation Results}

The detection limits of propionic and sorbic acids together with the concentration ranges, and the expected and obtained concentrations expressed in $\mathrm{mg} / \mathrm{kg}$ of bread are summarized in Tables 2 and 3, respectively. Linearity for propionic acid was verified between 210 and $2519.7 \mathrm{mg} / \mathrm{kg}$ bread, and for sorbic acid between 195.7 and $2348.1 \mathrm{mg} / \mathrm{kg}$ bread. The limits of detection and quantification were $94 \mathrm{mg} / \mathrm{kg}$ and $314 \mathrm{mg} / \mathrm{kg}$ for propionic acid and $258 \mathrm{mg} / \mathrm{kg}$ and $849 \mathrm{mg} / \mathrm{kg}$ for sorbic acid. The mean recovery rate for propionic acid was $76.1 \%$. For sorbic acid it was $57.5 \%$. Table 2 shows that there was a loss of propionic acid during the analytical process, e.g., during the sample preparation and measurement steps. Most probably, the loss occurred during the distillation step, which is based on a rather old German Official Method developed in 1985. Table 3 similarly 
shows that admixtures 1 to 4 had very low recovery values (less than $70 \%$ ). Hence, future research could work towards optimizing the sample preparation. On the other hand, the current procedure is quickly and easily to conduct and does not require further enrichment steps, because high dilution during distillation is avoided. The procedure rather underthan overestimates the content; therefore, we believe that exceedances of maximum limits would be provable with sufficient levels of certainty.

Table 2. The theoretical and experimental concentration expressed in $\mathrm{mg} / \mathrm{kg}$ as well as the recovery values (\%) of propionic acid in bread samples.

\begin{tabular}{cccc}
\hline Type & \multicolumn{2}{c}{$\begin{array}{c}\text { Concentration }(\mathbf{i n ~} \mathbf{m g} / \mathbf{k g}) \\
\text { Theoretical }\end{array}$} & Recovery (\%) \\
\hline Bread without & 0 & 0 & 0 \\
admixture & 205.6 & 260.4 & 79.0 \\
Admixture 1 & 398 & 520.7 & 76.4 \\
Admixture 2 & 777.8 & 1041.5 & 74.7 \\
Admixture 3 & 2325.6 & 3124.4 & 74.4 \\
Admixture 4 & & & \\
\hline
\end{tabular}

Table 3. The theoretical and experimental concentration expressed in $\mathrm{mg} / \mathrm{kg}$ as well as the recovery values (\%) of sorbic acid in bread samples.

\begin{tabular}{cccc}
\hline \multirow{2}{*}{ Type } & \multicolumn{2}{c}{ Concentration (in mg/kg) } & \multirow{2}{*}{ Recovery (\%) } \\
& Experimental & Theoretical & \\
\hline Bread without & 0 & 0 & 0 \\
admixture & 157.2 & 242.6 & 64.8 \\
Admixture 1 & 289.2 & 485.3 & 59.6 \\
Admixture 2 & 486.2 & 970.5 & 50.1 \\
Admixture 3 & 1618.2 & 2911.6 & 55.6 \\
Admixture 4 & & \\
\hline
\end{tabular}

The use of propionic and sorbic acid reference standards enabled precise assignment of chemical shifts. The information used for identification and quantification of both acids is shown in Tables 4 and 5 . The characteristic signals can be assigned to the corresponding analytes unambiguously and without overlapping (Figure 1).

Table 4. Chemical shifts, signal type, and number of protons for NMR identification of sorbic and propionic acid.

\begin{tabular}{ccccccc}
\hline Substance & \multicolumn{2}{c}{ Propionic Acid } & \multicolumn{3}{c}{ Sorbic Acid } \\
\hline ppm & 1.08 & 2.39 & 1.84 & 5.82 & 6.31 & 7.33 \\
Signal type & Triplet & Quartet & Doublet & Doublet & Multiplate \\
Number of protons & 3 & 2 & 3 & 1 & 2 & 1 \\
\hline
\end{tabular}

Table 5. Information for NMR quantification of sorbic and propionic acid.

\begin{tabular}{|c|c|c|c|c|c|c|c|c|}
\hline \multirow{2}{*}{ Analyte } & \multirow{2}{*}{ CAS-No } & \multirow{2}{*}{$\mathrm{M} /(\mathrm{g} / \mathrm{mol})$} & \multirow{2}{*}{$\delta / \mathrm{ppm}$} & \multirow{2}{*}{ Multiplet } & \multirow{2}{*}{$\mathrm{J} / \mathrm{Hz}$} & \multicolumn{2}{|c|}{ Integration } & \multirow{2}{*}{$N(\mathrm{H})$} \\
\hline & & & & & & from/ppm & to/ppm & \\
\hline Propionic acid & 79-09-4 & 74.08 & 1.082 & $\mathrm{t}$ & 7.5 & 1.117 & 1.045 & 3 \\
\hline Sorbic acid & $110-44-1$ & 112.13 & 1.846 & d & 5.0 & 1.875 & 1.820 & 3 \\
\hline
\end{tabular}




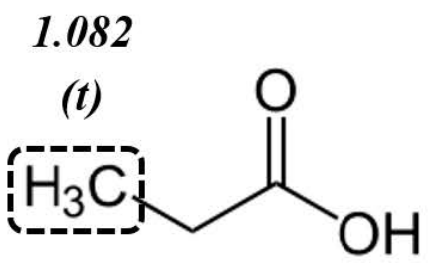

A) 2.391

(q)

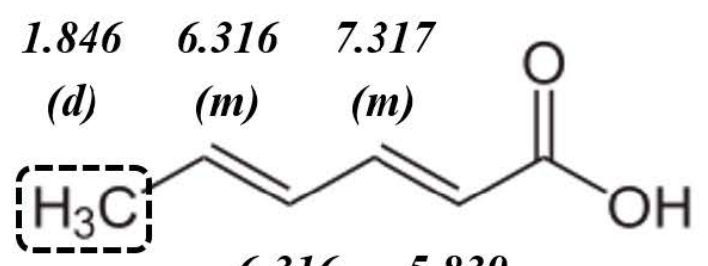

B)

6.316

(m)

(d)

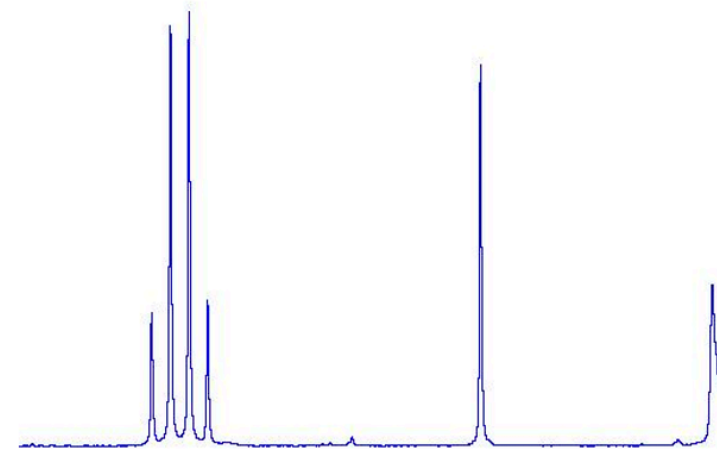

\section{B)}

2.5

2.0

1.5

$1.0 \quad$ [ppm]

Figure 1. Structural formula of (A) propionic acid, (B) sorbic acid (upper panels) and assignment of ${ }^{1} \mathrm{H}-\mathrm{NMR}$ signals of A) propionic acid, B) sorbic acid, and C) ethanol- $\mathrm{CH}_{3}$, with top of triplet cut off (lower panel).

\subsection{Propionic and Sorbic Acids Contents in Bread and Bakery Samples}

A typical NMR spectrum of a positive sample including magnifications of target resonances is shown in Figure 2. Both compounds were observed in the low frequency region $\delta 1-1.3 \mathrm{ppm}$. The green spectrum represents an admixture with added standard substances while the red spectrum represents the sample.

From 76 fresh bread samples (i.e., not prepacked bread), none of the samples contained either sorbic or propionic acid. On the other hand, from 21 prepacked bakery wares, 10 samples contained sorbic acid, but none of them contained propionic acid (Table 6). It must be noted that the recorded sorbic acid concentrations, apart from in one sample, were lower than the maximum permitted levels (Table 6). A yufka sample contained both acids. The yufka sample was also exceptional, because it did not provide labelling of the contained acids, which is an infringement of the EU food information laws. 


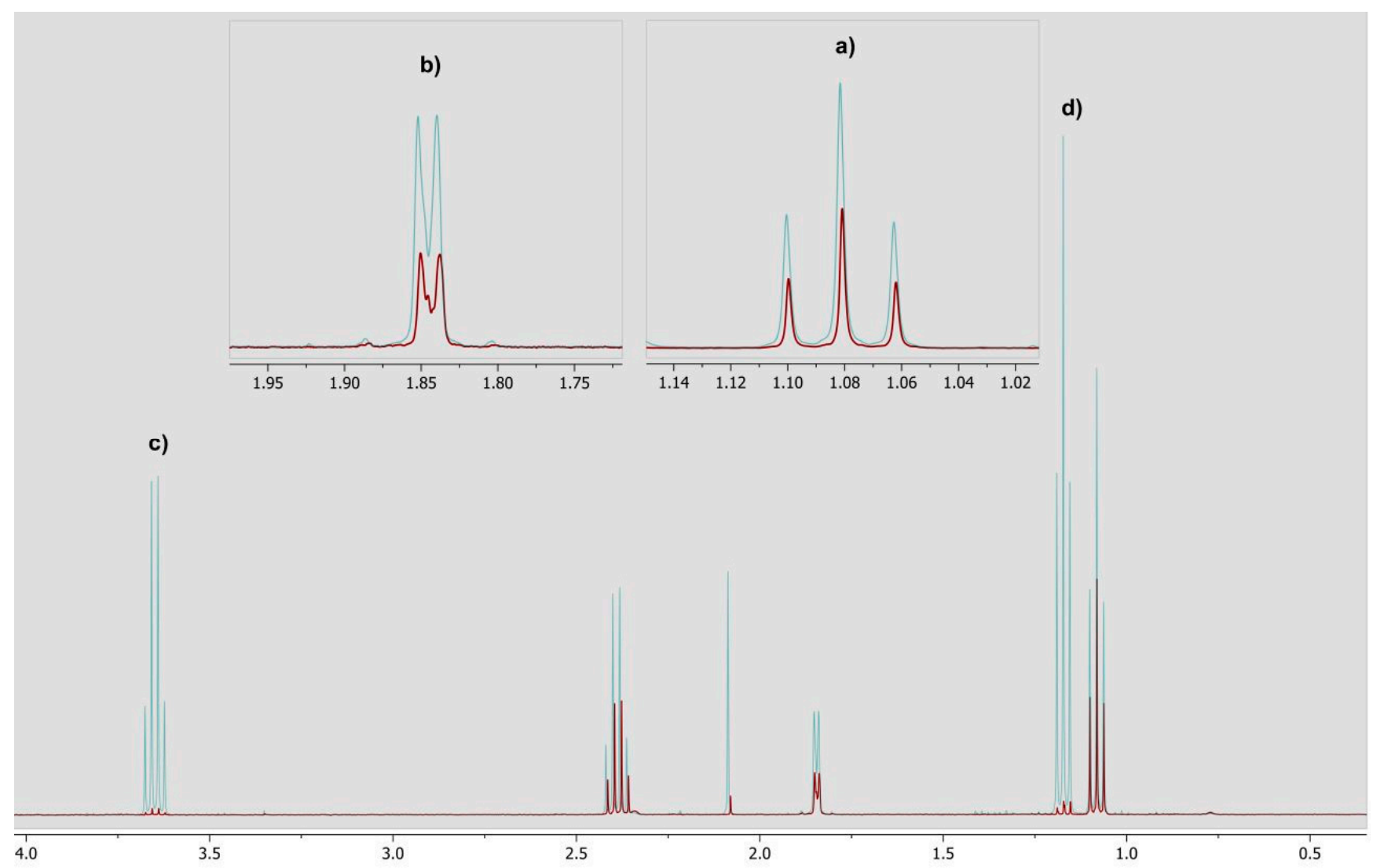

Figure 2. Representative ${ }^{1} \mathrm{H}$ NMR spectra of target additives in yufka bread sample: (a) propionic acid; (b) sorbic acid (c) ethanol- $\mathrm{CH}_{2} ;(\mathbf{d})$ ethanol- $\mathrm{CH}_{3}$ ( $x$-axis: ppm, $y$-axis arbitrary units).

Table 6. Propionic acid and sorbic acid concentration expressed in $\mathrm{mg} / \mathrm{kg}$ in all analyzed samples (n.d. not detectable (propionic acid: < $94 \mathrm{mg} / \mathrm{kg}$; sorbic acid: $<258 \mathrm{mg} / \mathrm{kg}$ ).

\begin{tabular}{|c|c|c|c|c|}
\hline \multicolumn{5}{|c|}{ Concentration (mg/kg) } \\
\hline \multirow{2}{*}{$\begin{array}{l}\text { Bread, Not Prepackaged } \\
\qquad(n=76)\end{array}$} & \multicolumn{2}{|c|}{$\begin{array}{l}\text { Yufka, Pasta } \\
\quad(n=2)\end{array}$} & \multicolumn{2}{|c|}{$\begin{array}{l}\text { Rye-Bread, Partially Baked, Prepacked Bakery Wares } \\
\qquad(n=21)\end{array}$} \\
\hline & Sorbic Acid & Propionic Acid & Sorbic Acid & Propionic Acid \\
\hline \multirow{10}{*}{ n.d. (all samples) } & \multirow{10}{*}{1183} & \multirow{10}{*}{1288} & 1005 & n.d. \\
\hline & & & 1872 & n.d. \\
\hline & & & 1453 & n.d. \\
\hline & & & 1502 & n.d. \\
\hline & & & 1770 & n.d. \\
\hline & & & 2173 & n.d. \\
\hline & & & 1399 & n.d. \\
\hline & & & 1885 & n.d. \\
\hline & & & 1235 & n.d. \\
\hline & & & 1300 & n.d. \\
\hline
\end{tabular}

\subsection{Measures Accompanying the Analysis}

The method is suitable for clearly identifying propionic and sorbic acid in bread. The signals are specific. The method is also suitable for the quantitative determination of propionic acid in bread. It covers the usual concentrations for this matrix (undetectable up to the currently accepted maximum levels ranging between $1000 \mathrm{mg} / \mathrm{kg}$ and $3000 \mathrm{mg} / \mathrm{kg}$ ). For sorbic acid, the method provides only guidance values due to low recoveries. The determined limits of quantification are sufficient for routine tests. Each measurement series was accompanied by quality control samples. The quality control charts (Figure 3) 
show sufficient long-term stability of the assay. The slight downward trend was judged as being due to potential loss of the acids due to evaporation or chemical degradation during storage rather than due to problems with measurement or spectrometers.
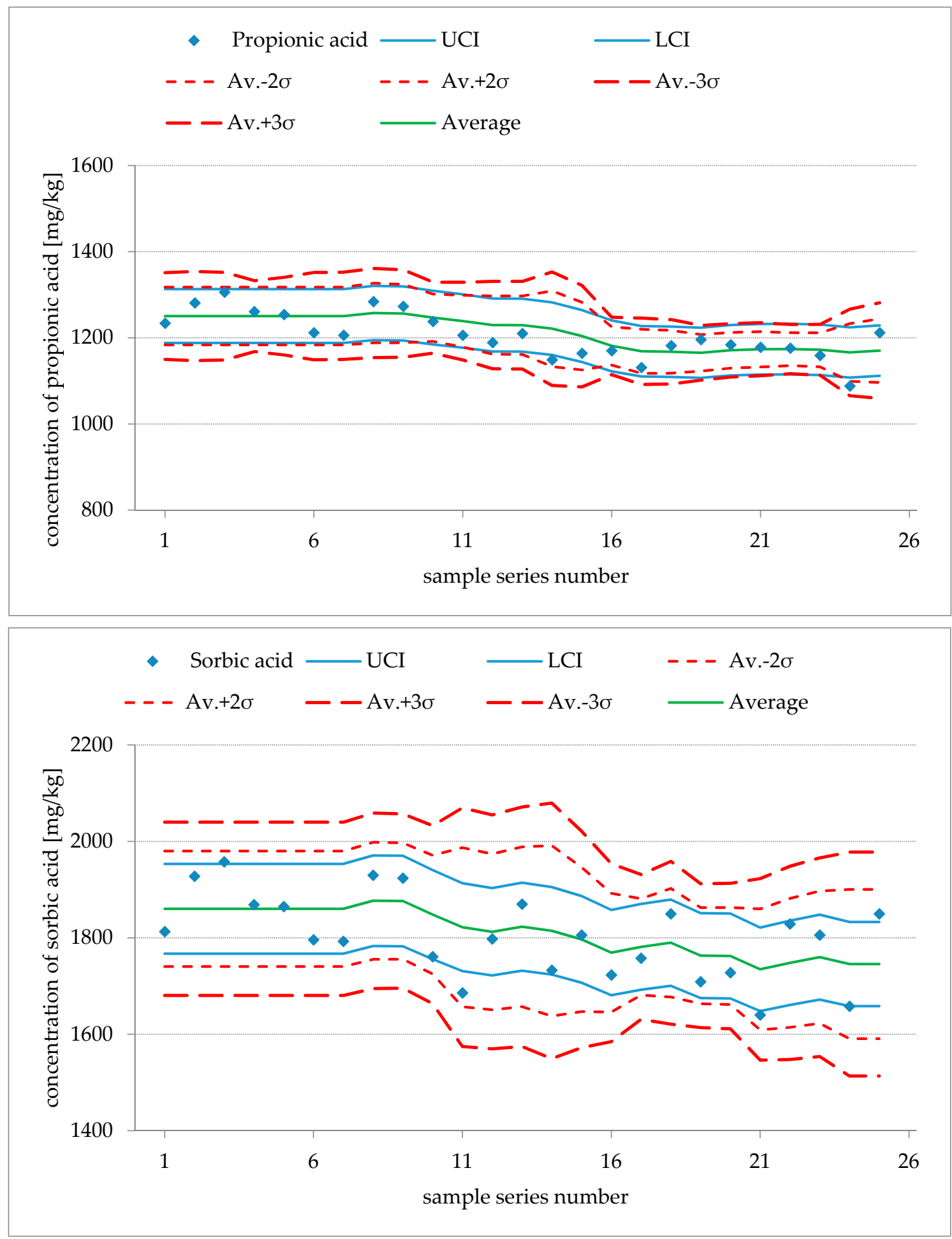

Figure 3. Quality control charts for propionic acid (upper panel) and sorbic acid (lower panel) ( $x$-axis, sample series number; $y$-axis, concentration in $\mathrm{mg} / \mathrm{kg}$ ). By analyzing an aliquot of a reproducibility assessment sample with each new sample batch, for both analytes their respective rolling averages and accompanying spans of two and three standard deviations are calculated and monitored. Thus, deviations due to process faults can be detected. The range of $2 \cdot \sigma$ contains $95 \%$ and the range of $3 \cdot \sigma$ contains $99.7 \%$ of the probable results. 


\section{Discussion}

Accompanying the technological development and modernization of food production and processing, the quality control of finished products has received the attention of a large range of scientific studies. These have been oriented towards the analysis of the effectiveness of the quality control as well as the quality and integrity of food additives. Despite this, fraud was constantly occurring in terms of incorrect labelling of the product or the type and origin of ingredients. Therefore, fully automated NMR spectroscopy, combined with multivariate data analysis techniques, has proven to be an efficient multipurpose tool to address these challenges $[9,13,17]$.

As a matter of principle, recovery measurements are expressed in terms of the addition of a known amount of analyte to a sample and then determining the percent of the added amount. Food samples can therefore be spiked with varying amounts of a pure standard to give concentrations at the upper and lower reference limits [18]. Therefore, the recovery rate is usually given in percent and it describes the benchmarks for evaluating the quality of chemical analytical methods. It is defined as "the ratio of the amount of an analyte that is added to a sample before sample preparation and the amount of this analyte that is found as the measurement result" [16]. According to the same guidelines, if the recovery rate of an analyte is $100 \%$, there has been no loss of this analyte during the entire analytical process (through particular analytical steps such as extraction and measurement). However, if the recovery rate is lower than $70 \%$, this is an indication of substance loss. The percentage of losses can be verified by using additional internal standards or a recovery function $[18,19]$.

Some evidence in the literature concluded that if the recovery observed for a spiked solution is identical to or iterates around $10 \%$ of the added concentration, the accuracy of the assay is considered as sufficient $[19,20]$. We have observed similar patterns in some spiked samples, especially in the case of propionic acid. As for sorbic acid, the recorded recovery rates did not fit the general IUPAC criteria [18].

In this study, the developed NMR method showed efficiency in detecting propionic and sorbic acids amounts in all analyzed bread samples. Nevertheless, we have observed that for both compounds, missing information were observed in the list of ingredients in some packaging (e.g., yufka samples). Furthermore, according to Article (18), paragraph (4) in connection with Annex VII, Part C of regulation (EU) No. 1169/2011 in regard to the provision of food information to consumers, food additives must be named according to their respective class. More attention should be drawn to the labelling and the use of the correct class designation in bread samples.

\section{Conclusions}

Our study is the first to provide NMR validation results for propionic and sorbic acid contents in bread and bakery products. The validated results showed that the developed method is quick and reproducible regarding the quantitative analysis of both substances. In order to use the developed NMR analysis for quality control of a broad range of cereals, further validation studies for other matrices (e.g., semolina, corn, doughs, dry mixes) is worthwhile. Nevertheless, further investigations of the sample preparation of both acids are necessary to increase the recovery rates, because the loss is expected to occur during the distillation step rather than the NMR measurement.

Author Contributions: Conceptualization, D.W.L.; methodology, A.S., T.K., J.T. and D.W.L.; formal analysis, A.S.; resources, S.G.W. and D.W.L.; data curation, A.S.; writing original draft preparation, M.S.; writing—review and editing, D.W.L., M.K., J.T., A.S., T.K., and S.G.W.; supervision, D.W.L. and S.G.W. All authors have read and agreed to the published version of the manuscript.

Funding: This research received no external funding.

Institutional Review Board Statement: Not applicable.

Informed Consent Statement: Not applicable.

Data Availability Statement: The data are not publicly available due to government policies. 
Acknowledgments: The team of the laboratory for plant-based foods at CVUA Karlsruhe is thanked for their careful sample preparation and support in validation works.

Conflicts of Interest: The authors declare no conflict of interest.

\section{References}

1. Spencer, M. Food additives. Postgrad. Med. J. 1974, 50, 620-624. [CrossRef] [PubMed]

2. FAO/WHO Joint Expert Committee on Food Additives. Sorbic acid and its calcium, potassium and sodium salts. In Toxicological Evaluation of Some Food Additives Including Anticaking Agents, Antimicrobial, Antioxidants, Emulsifiers and Thickening Agents; WHO Food Additive Series, No. 5; World Health Organization: Geneva, Switzerland, 1974; pp. 121-127.

3. FAO/WHO Joint Expert Committee on Food Additives. Saturated aliphatic acyclic linear primary alcohols, aldehydes, and acids. In Safety Evaluation of Certain Food Additives and Contaminants; WHO Food Additives Series 40, Forty-ninth Meeting of the Joint FAO/WHO Expert Committee on Food Additives; WHO: Geneva, Switzerland, 1998.

4. The European Parliament and the Council of the European Union. Regulation (EC) No 1333/2008 of the European Parliament and of the Council of 16 December 2008 on food additives. Off. J. Eur. Union 2008, L354, 16-33.

5. EFSA ANS Panel (EFSA Panel on Food Additives and Nutrient Sources Added to Food). Scientific Opinion on the re-evaluation of propionic acid (E 280), sodium propionate (E 281), calcium propionate (E 282) and potassium propionate (E 283) as food additives. EFSA J. 2014, 12, 3779. [CrossRef]

6. Libert, M.A. Final Report on the Safety Assessment of Sorbic Acid and Potassium Sorbate. J. Am. Coll. Toxicol. 1988, 7, 837-879. [CrossRef]

7. EFSA ANS Panel (EFSA Panel on Food Additives and Nutrient Sources added to Food). Scientific opinion on the safety of the extension of use of sodium propionate (E 281) as a food additive. EFSA J. 2016, 14, 4546. [CrossRef]

8. EFSA FAF Panel (EFSA Panel on Food Additives and Flavourings). Scientific Opinion on the follow-up of the re-evaluation of sorbic acid (E200) and potassium sorbate (E202) as food additives. EFSA J. 2019, 17, 5625. [CrossRef]

9. Okaru, A.; Scharinger, A.; de Rezende, T.R.; Teipel, J.; Kuballa, T.; Walch, S.; Lachenmeier, D. Validation of a Quantitative Proton Nuclear Magnetic Resonance Spectroscopic Screening Method for Coffee Quality and Authenticity (NMR Coffee Screener). Foods 2020, 9, 47. [CrossRef] [PubMed]

10. Chen, M.T.; Hsu, Y.H.; Wang, T.S.; Chien, S.W. Mycotoxin monitoring for commercial foodstuffs in Taiwan. J. Food Drug Anal. 2016, 24, 147-156. [CrossRef] [PubMed]

11. Phechkrajang, C.M.; Yooyong, S. Fast and simple method for semi-quantitative determination of calcium propionate in bread samples. J. Food Drug Anal. 2017, 25, 254-259. [CrossRef] [PubMed]

12. Al Azzam, K.M.; Bahruddin, S.; Hashim, N.H.; Rahim, A.A.; Talib, K.M. Determination of propionates and propionic acid in bakery products using gas chromatography. Int. Food Res. 2010, 17, 1107-1112.

13. Monakhova, Y.B.; Kuballa, T.; Lachenmeier, D.W. Nontargeted NMR analysis to rapidly detect hazardous substances in alcoholic beverages. Appl. Magn. Res. 2012, 42, 343-352. [CrossRef]

14. Maes, P.; Monakhova, Y.B.; Kuballa, T.; Reusch, H.; Lachenmeier, D.W. Qualitative and quantitative control of carbonated cola beverages using ${ }^{1} \mathrm{H}$ NMR spectroscopy. J. Agric. Food Chem. 2012, 60, 2778-2784. [CrossRef] [PubMed]

15. Technical Rule (Current). Technical Rule (Current). Untersuchung von Lebensmitteln. Untersuchung von Lebensmitteln; Bestimmung von Propionsäure in Brot. BVL L 17.00-14: Beuth Publishing: Berlin. Available online: https://www.beuth.de/en/ technical-rule/bvl-1-17-00-14/717647 (accessed on 2 March 2021). 1987-06.

16. Lachenmeier, D.W.; Plato, L.; Suessmann, M.; Di Carmine, M.; Krueger, B.; Kukuck, A.; Kranz, M. Improved automatic steam distillation combined with oscillation-type densimetry for determining alcoholic strength in spirits and liqueurs. SpringerPlus 2015, 4, 783. [CrossRef] [PubMed]

17. Spraul, M.; Schütz, B.; Rinke, P.; Koswig, S.; Humpfer, E.; Schäfer, H.; Mörtter, M.; Fang, F.; Marx, C.U.; Minoja, A. NMR-Based Multi Parametric Quality Control of Fruit Juices: SGF Profiling. Nutrients 2009, 1, 148-155. [CrossRef] [PubMed]

18. Burns, D.T.; Danzer, K.; Townshend, A. Use of the term "recovery" and "apparent recovery" in analytical procedures (IUPAC Recommendations 2002). Pure Appl. Chem. 2002, 74, 2201-2205. [CrossRef]

19. Monakhova, Y.B.; Schütz, B.; Schäfer, H.; Spraul, M.; Kuballa, T.; Hahn, H.; Lachenmeier, W.D. Validation studies for multicomponent quantitative NMR analysis: The example of apple fruit juice. Accred. Qual. Assur. 2014, 19, 17-29. [CrossRef]

20. International Organization for Standardization (ISO). ISO/IEC 17025: 2005 General Requirements for the Competence of Testing and Calibration Laboratories; ISO: Geneva, Switzerland, 2005. 